\title{
COLLEGIANS' READINESS TO CONSUME GRAINS: THE TRANSTHEORETICAL MODEL OF CHANGE AS A THEORETICAL FRAMEWORK
}

\section{Tiba Hayder Hadi ${ }^{1}$ and Mohammed Baqer Habeeb Abd Ali ${ }^{2}$ *}

1. Ministry of Health, Baghdad Health Directorate, Iraq;

2. Department of Community Health Nursing, College of Nursing, University of Baghdad, City of Baghdad, Iraq.

\section{Corresponding author: Tiba Hayder Hadi}

Email: Tibahaider56@gmail.com

ORCID

\section{ABSTRACT}

A descriptive predictive design was used to guide this study. The study was conducted in Al-Qadisiyah University. The study included a convenience sample of 400 undergraduate students. The study instrument includes students' sociodemographic sheet of age, gender, marital status, and grade. It also includes Stages of Change Scale for Grain Consumption, The Decisional Balance Scale for Grain Consumption, The Self-Efficacy Scale for Grain Consumption. Data Collection: Data were collected using an online google form for the period from March 5th, 2021 to April 22 nd, 2021. Data were analyzed using the statistical package for social science, version 26 . The descriptive statistical measures of frequency, percent, mean, and standard deviation were used to describe subjects' sociodemographic characteristics. The inferential statistical measures of linear regression, Independent-Sample T-Test, and One-Way Analysis of Variance. The study results revealed that around a half were in the Contemplation Stage of Change for consuming grains, followed by those who are in the Preparation Stage of Change, and those who are in the Maintenance Stage of Change. According to the findings, the higher the family's socioeconomic position, the higher the perceived value of eating grains. Grains consumption has more drawbacks when one's BMI rises. There is a need by the community health nurses; in collaboration with Iraqi Ministry of Health and Mass Media, to initiate health education materials that raise the health awareness of individuals who are both overweight and obese about the vital role of consuming grain. There is a need to incorporate materials that highlight the vital role of consuming each of grain regularly into the curricula of various educational levels in Iraq.

Keywords: The Transtheoretical Model; grains consumption

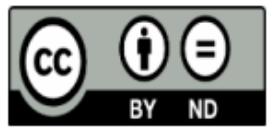

This work is licensed under a Creative Commons Attribution Non-Commercial 4.0 International License.

Received: 01 June 2021, Accepted: 19 July 2021, Available online: 20 January 2022 


\section{INTRODUCTION}

The meals and drinks that people consume have a significant impact on their health. Scholars have thoroughly documented the relationship between food and health for decades, demonstrating that following appropriate dietary patterns may help people attain and maintain good health and reduce the risk of chronic disease throughout their lives. (U.S. Department of Agriculture [USDA], 2020).

The World Health Organization, in line with dietary guidelines around the globe, recognizes whole grains as an important component of a healthy diet (World health organization, 2020).

Nowadays, consumers are more conscious of the environmental and nutritional benefits of foods. Pseudocereals grains, edible seeds belonging to dicotyledonous plant species, are becoming a current trend in human diets as gluten-free (GF) grains with excellent nutritional and nutraceutical value. Pseudocereals are a good source of starch, fiber, proteins, minerals, vitamins, and phytochemicals such as saponins, polyphenols, phytosterols, phytosteroids, and betalains with potential health benefits.( Martínez-Villaluenga et al., 2020)

Chronic illnesses such as cardiovascular disease (CVD), hypertension, obesity, stroke, osteoporosis, diabetes, and cancers such as breast cancer, colorectal cancer, bladder cancer, and lung cancer, as well as cancers such as breast cancer, colorectal cancer, bladder cancer, and lung cancer (Farvid et al., 2019; Lee et al., 2017; Vieira et al., 2015; Wang et al., 2015) Global health concerns, such as high all-cause mortality, are a source of death and impairment for millions of people (Anderson \& Durstine, 2019). Grains have been found to protect against the development of certain chronic illnesses (Toups et al., 2020).

The presence of phytochemicals, which function as antioxidants, is one of the reasons that veggies help to prevent illnesses. (Tang et al.,2017).

\section{METHOD}

A descriptive predictive design will be used to guide this study, The study was carried out at AlQadisiyah University. The study subjects were recruited from 10 colleges in this university which College of Medicine, College of Dentistry, College of Veterinary Medicine, College of Pharmacy, College of Nursing, College of Administration and Economics, College of Science, College of Sports, College of Law, College of Education. A nonprobability convenience sample of (400) students who are enrolled in the aforementioned colleges based on a margin of error of $5 \%$, confidence level of $95 \%$, a population size of 18,000 , and response distribution of $50 \%$, the recommended sample size is $\mathbf{3 7 7}$, the final size is 400 . The study instrument is composed of three parts and these parts are: Students Sociodemographic Sheet: This part includes the variables of (age, gender, grade, living arrangement, marital status, residency, level of education, household socioeconomic status which encompasses parents' level of education, a household's occupation, and family's monthly income). The study instrument included the body mass index which is calculated by dividing the body weight (kilogram) by body height $(m) 2$. The Stages of Change Scale A discrete specification of the criterion behavior for sufficient consumption is included in this scale (a discrete definition of consuming grins). The staging tool's items evaluated the reported level of current intake for each food (grains), as well as consistency and duration of consumption at a reported level, which was designed (26). The researcher used the Arabic version (27). All participants were asked to answer "yes" or "no" to questions on how many portions of each meal they consumed each day. (26) created a summary index, which refers to the expected relative balancing of the benefits (Pros) and drawbacks (Cons) of eating more vegetables. The researcher used the Arabic version (27). The Pros (10 items) and Cons (10 items) highlighted respondents' perceptions of barriers and benefits important in their decision to increase consumption of grains products. These items were measured using a on a five-point Likert type scale ranging from one for (not important at all) to five for (very important). young adults can consume the recommended amounts of grains day, irrespective of their situation this situation-specific called SelfEfficacy. This scale includes 20 items that are measured on a visual analog scale that ranges from one for (not confident at all) to nine for (very confident). The scores of Self-Efficacy range from 20 to 180 . Higher scores indicate greater selfconfidence for consuming the aforementioned foods. Data were collected using an online survey "google form".

\section{Statistical analysis}

The collected data were compiled and analysed using percentages, mean, median, and Chi-square tests using SPSS version 26. P values of 0.05 were used as a cut-off point for the significance of the statistical test.

\section{RESULTS}

The findings in Table (1) shows that the mean of age is $22.79 \pm 3.19$; most age 18-24-years $(n=309$; 
$77.25 \%)$, followed by those whose age 25-30-years $(n=79 ; 19.75 \%)$, and those whose age 31 -36-years $(n=12 ; 3.0 \%)$.

Concerning the gender, the most are females $(\mathrm{n}=$ $276 ; 69.0 \%)$ compared to males $(n=124 ; 31.0 \%)$. Regarding marital status, the majority are not married $(n=333 ; 83.25 \%$, followed by those who are married $(\mathrm{n}=61 ; 15.25 \%)$, those who are widow/widower $(n=4 ; 1.0 \%)$, and those who are divorced $(n=2 ; 0.05 \%)$.

With respect to grade, more than a quarter are fourth graders $(n=105 ; 26.25 \%)$, followed by those who are third graders $(n=94 ; 23.5 \%)$, those who are first graders $(n=77 ; 19.25 \%)$, those who are fifth graders $(n=40 ; 10.0 \%)$, and those who are sixth graders $(n=20 ; 5.0 \%)$.

Concerning the living arrangement, most reported that they have been living with parents $(n=300$; $75.0 \%$ ), followed by those who have other living arrangement $(n=44111.0 \%)$, those who have been living with mother $(n=43 ; 10.75 \%)$, those who have been living with father $(n=9 ; 2.25 \%)$,

and those who both have been living with relatives and friends $(n=2 ; 0.5 \%)$ for each of them.

Regarding residency, most reported that they have been living in urban areas $(n=254 ; 63.5 \%)$, followed by those who have been living in suburban areas ( $\mathrm{n}=90 ; 22.5 \%)$, and those who have been living in rural areas $(n=56 ; 14.0 \%)$.

With respect to family's socioeconomic status, the socioeconomic status for more than a third is of lower middle class $(n=143 ; 35.75 \%)$, followed by those who are of upper middle class ( $n=137$; $34.25 \%)$, those who are of upper lower class $(n=$ 98; $24.5 \%)$, those who are of upper class $(n=18$; $4.5 \%)$, and those who are of lower class ( $n=4$; $1.0 \%)$.

Table (2) Show that most enjoy within normal proportion of body weight-to-height $(n=261$; $65.25 \%$ ), followed by those who are overweight ( $\mathrm{n}$ = 98; 24.5\%), those who are underweight $(n=23$; $5.75 \%)$, those who are with obesity class I $(n=14$; $3.5 \%)$, and those who are with obesity class II ( $\mathrm{n}=$ $4 ; 1.0 \%)$.

Around a half are in the Contemplation Stage of Change for consuming grains ( $n=198 ; 49.5 \%$ ), followed by those who are in the Preparation Stage of Change $(n=111 ; 27.75 \%)$, and those who are in the Maintenance Stage of Change $(n=91$; $22.75 \%$ ), as shown in table (3).

Table (4) shows that is a statistically significant difference in Self-Efficacy for the consumption of vegetables among family's socioeconomic class groups $(p$-value $=.05)$.

Table 1. Participants' sociodemographic characteristics $(N=400)$

\begin{tabular}{|c|c|c|}
\hline Variable & Frequency & Percent \\
\hline \multicolumn{3}{|l|}{ Age (Years): Mean (SD) $=22.79 \pm 3.19$} \\
\hline $18-24$ & 309 & 77.25 \\
\hline $25-30$ & 79 & 19.75 \\
\hline $31-36$ & 12 & 3.0 \\
\hline \multicolumn{3}{|l|}{ Gender } \\
\hline Male & 124 & 31.0 \\
\hline Female & 276 & 69.0 \\
\hline \multicolumn{3}{|l|}{ Marital Status } \\
\hline Not married & 333 & 83.25 \\
\hline Married & 61 & 15.25 \\
\hline Divorced & 2 & 0.5 \\
\hline Widow/Widower & 4 & 1.0 \\
\hline \multicolumn{3}{|l|}{ Grade } \\
\hline First & 77 & 19.25 \\
\hline Second & 64 & 16.0 \\
\hline Third & 94 & 23.5 \\
\hline Fourth & 105 & 26.25 \\
\hline Fifth & 40 & 10.0 \\
\hline Sixth & 20 & 5.0 \\
\hline
\end{tabular}




\begin{tabular}{lcc}
\hline Living Arrangement & 300 & 75.0 \\
Live with parents & 43 & 10.75 \\
Live with my mother & 9 & 2.25 \\
Live with my father & 2 & 0.5 \\
Live with my relatives & 2 & 0.5 \\
Live with my friends & 44 & 11.0 \\
Other & & \\
\hline Residency & 254 & 63.5 \\
Urban & 56 & 14.0 \\
Rural & 90 & 22.5 \\
Suburban & & \\
\hline Socioeconomic status & 4 & $\mathbf{1 . 0}$ \\
Lower class & 98 & $\mathbf{2 4 . 5}$ \\
Upper lower class & $\mathbf{3 5}$ & $\mathbf{3 5 . 7 5}$ \\
Lower middle class & $\mathbf{1 4 3}$ & $\mathbf{3 4 . 2 5}$ \\
Upper middle class & 137 & $\mathbf{4 . 5}$ \\
\hline Upper class & 18 & \\
\hline
\end{tabular}

Table 2. Participants' distribution according to their body mass index

\begin{tabular}{|c|c|c|}
\hline BMI Category & Frequency & Per cent \\
\hline Underweight & 23 & 5.75 \\
\hline Within normal & 261 & 65.25 \\
\hline Overweight & 98 & 24.5 \\
\hline Obesity Class I & 14 & 3.5 \\
\hline Obesity Class II & 4 & 1.0 \\
\hline
\end{tabular}

Table 3. Participants' distribution according to their readiness to consume grain

\begin{tabular}{lccc}
\hline & Stages of Change & Frequency & Percent \\
\hline Contemplation & & 198 & 49.5 \\
Preparation & 111 & 27.75 \\
Maintenance & 91 & 22.75 \\
\hline
\end{tabular}

Table 4. The difference in Self-Efficacy for consumption of vegetables among family's socioeconomic class groups

\begin{tabular}{cccccc}
\hline \multicolumn{5}{c}{ ANOVA } \\
& Self-Efficacy Vegetables & F & Sig. \\
Between Groups & Sum of Squares & $\mathrm{df}$ & Mean Square & 2.497 & .042 \\
Within Groups & 12675.461 & 4 & 3168.865 & & \\
Total & 501374.337 & 395 & 1269.302 & 2.497 & .042 \\
\hline
\end{tabular}

\section{DISCUSSION}

Around half were in the Contemplation Stage of Change for consuming grains, followed by those who are in the Preparation Stage of Change, and those who are in the Maintenance Stage of Change. These findings; according to the Transtheoretical Model of Behavior Change, imply that around a half intends to take action "consuming grain" regularly within the next 6 months. This finding is consistent with that obtained by Greene et al. (2003) who stated that the majority of subjects were in the Precontemplation Stage of Change.

There is a statistically significant difference in Self-Efficacy for consumption of grain among family's socioeconomic class groups. Except for students from families with upper socioeconomic class, further post hoc analysis displays that the better the socioeconomic status, 
the greater the Self-Efficacy for consuming grain. This finding could be interpreted as that family whose socioeconomic status is better enabled them to shop foods that contain whole grains compared with families whose socioeconomic status is poor which hinders them from shopping for such foods.

\section{CONCLUSIONS}

The researcher concluded that: the better the family's socioeconomic status, the greater the perceived value of consuming grains. The poorer the family's socioeconomic status, the greater the Cons of consuming grains. The greater the BMI, the greater the Cons of consuming grains.

\section{ETHICAL CONSIDERATIONS COMPLIANCE WITH ETHICAL GUIDELINES}

This study was completed following obtaining consent from the University of Baghdad.

\section{FUNDING}

This research did not receive any grant from funding agencies in the public, commercial, or non-profit sectors.

\section{AUTHOR'S CONTRIBUTIONS}

Study concept, Writing, Reviewing the final edition by all authors.

DISCLOSURE STATEMENT: The authors report no conflict of interest.

\section{ACKNOWLEDGEMENTS}

We thank the anonymous referees for their useful suggestions.

\section{REFERENCES}

Abd Ali, M. B. (n,d,). Psychometric properties of the Arabic version of the Transtheoretical Model of Change for Fruits and Vegetables Consumption. Unpublished paper.

Anderson, E., \& Durstine, J. L. (2019). Physical Activity, Exercise, and Chronic diseases: A brief review. Sports Medicine and Health Science, 1(1), 3-10.

Farvid, M. S., Chen, W. Y., Rosner, B. A., Tamimi, R. M., Willett, W. C., \& Eliassen, A. H. (2019). Fruit and Vegetable consumption and Breast cancer Incidence: Repeated measures over 30 years of follow-up. International Journal of Cancer, 144(7), 1496-1510.

Greene, G., Horacek, T.M., White, A., \& Ma, J. (2003). Use of a Diet interview method to define Stages of Change in Young Adults for Fruit,
Vegetable, and Grain Intake. Topics in Clinical Nutrition, 18(1), 32-41. https://doi-

Lee, J., Shin, A., Oh, J. H., \& Kim, J. (2017). Colors of Vegetables and Fruits and the risks of colorectal Cancer. World Journal of Gastroenterology, 23(14), 2527.

Maina, S. N. (1999). Application of the Transtheoretical model of behavior Chang

Martínez-Villaluenga, C., Peñas, E., \& HernándezLedesma, B. (2020). Pseudocereal grains: Nutritional value, health benefits and current applications for the development of gluten-free foods. Food and Chemical Toxicology, 137, 111178.

Tang, Y., \& Tsao, R. (2017). Phytochemicals in quinoa and amaranth grains and their antioxidant, anti-inflammatory, and potential health beneficial effects: a review. Molecular Nutrition \& Food Research, 61(7), 1600767.

Toups, K. E. (2020). Global approaches to promoting whole grain consumption. Nutrition Reviews, 78(Supplement_1), 54-60.

U.S. Department of Agriculture [USDA]. (2020). Dietary guidelines for Americans 2020-2025. Washington, D.C.: U.S. Department of Agriculture [USDA].

Vieira, A. R., Vingeliene, S., Chan, D. S., Aune, D., Abar, L., Navarro Rosenblatt,

Vieira, A. R., Vingeliene, S., Chan, D. S., Aune, D., Abar, L., Navarro Rosenblatt, D., ... \& Norat, T. (2015). Fruits, Vegetables, and Bladder cancer risk: A systematic review and meta-analysis. Cancer medicine, 4(1), 136-146.

Wang, M., Qin, S., Zhang, T., Song, X., \& Zhang, S. (2015). The effect of Fruit and Vegetable Intake on the development of lung cancer: A meta-analysis of 32 publications and 20414 cases. European Journal of clinical nutrition, 69(11), 1184-1192.

World Health Organization. (2020). Healthy diet. Retrieved from https://www.who.int/newsroom/fact-sheets/detail/healthy-diet 